\title{
Robotics and Al in Food Security and Innovation: Why They Matter and How to Harness Their Power
}

\author{
Maximo Torero
}

\section{Contents}

Challenge: The Great Balancing Act $\ldots \ldots \ldots \ldots \ldots \ldots \ldots \ldots \ldots \ldots \ldots \ldots \ldots \ldots \ldots$

What Is Happening: Robotic Farming $\ldots \ldots \ldots \ldots \ldots \ldots \ldots \ldots \ldots \ldots \ldots \ldots \ldots \ldots \ldots \ldots . \ldots \ldots$

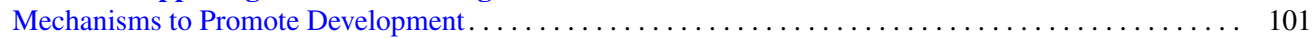

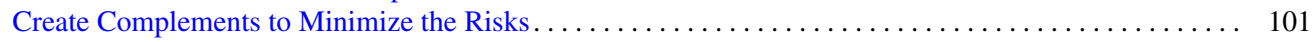

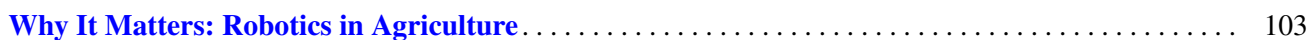

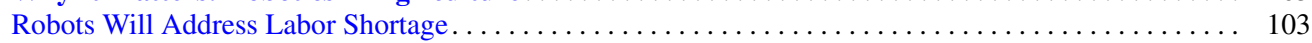

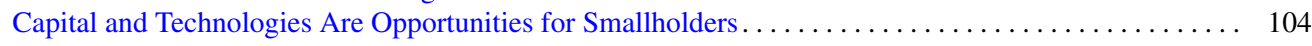

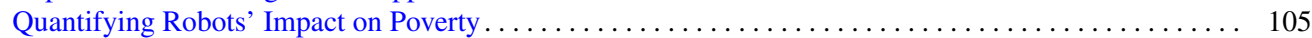

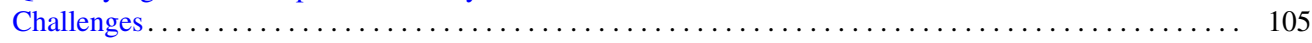

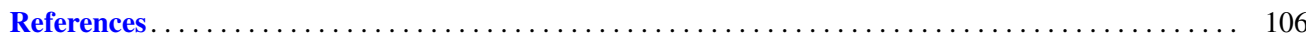

\section{Abstract}

From strawberry-picking robots to satellite remote sensing and GIS techniques that forecast crop yields, the integration of robotics and AI in agriculture will play a key role in sustainably meeting the growing food demand of the future. But it also carries the risk of alienating a certain population, such as smallholder farmers and rural households, as digital technologies tend to be biased toward those with higher-level skills. To ensure that digital technologies are inclusive and become a driver for development, countries should make technology affordable and invest in institutions and human capital, so that everyone can participate in the new digital economy. Digital agriculture also represents an opportunity for young people as agriculture value chains can be developed to create new service jobs in rural areas, making agriculture an attractive sector for youth.

M. Torero ( $\square)$

Chief Economist, Food and Agriculture Organization of the United

Nations, Rome, Italy

e-mail: maximo.torerocullen@fao.org

\section{Keywords}

Digital farming - Field robots - Agricultural economics · Innovation · Food security

\section{Challenge: The Great Balancing Act}

Feeding nearly 10 billion people by 2050 , while maintaining economic growth and protecting the environment is an urgent, unprecedented challenge. It is a challenge of managing trade-offs between the immediate need to produce food and the long-term goal of conserving the ecosystem. Robotics and artificial intelligence will play a crucial role in this. However, as digital technologies revolutionize, the risks of unequal access and digital exclusion loom large. Countries must make investments in human capital and put policies and regulations in place to minimize such risks and ensure that everyone, especially smallholders who produce the majority of the world's food, can participate in a new digital economy. 
To achieve sustainable food future, countries must meet the following needs simultaneously (Searchinger et al. 2013):

1. Close the gap between the amount of food available today and the amount that would be required in 2050. In order to do this, the world needs to increase food calories by $50 \%$ (FAO 2018).

2. Boost agricultural development, so that it can contribute to inclusive economic growth and social development. The agriculture sectors employ $28 \%$ of the global population and are still one of the most important pathways to help people escape poverty and hunger (World Bank 2019a).

3. Reduce environmental impact. Food production is the largest cause of environmental change globally. Agriculture contributes up to $29 \%$ of global greenhouse gas emissions (Vermeulen et al. 2012).

Additionally, countries must save water and protect land. Agriculture is the culprit of water scarcity, accounting for $70 \%$ of all water withdrawals (FAO 2019). About $40 \%$ of the world's land area is used for agriculture (Owen 2005). And the expansion of croplands and pastures undermines the capacity of ecosystems to sustain food production.

Climate variability will exacerbate food security in emerging economies (Torero 2016). Climate variability goes beyond extreme weather events and may include shifts in meteorological patterns. This could result in large-scale changes in agricultural sectors, causing major uncertainties and volatility. Even though this is integral information for food security and sustainable agriculture, policymakers have been slow to integrate this into long-term agricultural policy development.

\section{What Is Happening: Robotic Farming}

Mechanization has played a significant role in agriculture in the past. As shown in Fig. 1 below, mechanization was characterized by large farms (150-240 ha) focusing on increasing yields. The result of this process was a vicious cycle in which large farms adopted mechanization, increasing the competition for input and output markets, which then resulted in a more concentrated agricultural sector in terms of not only land but also input and output markets (see Fig. 1 below). This was identified earlier (Schmitz and Seckler 1970), but the social costs of past mechanization were never properly tackled.

Robotics is increasingly becoming a part of agriculture, but it is starting a different evolution process because of its potential to be scale neutral. This development can be broadly understood by studying what is happening at Amazon (Corke 2015) and other companies like Alibaba. Amazon's auto- mated fulfillment centers employ a large number of small robots that operate in parallel, optimizing the allocation of resources and automation processes. The robotics and technology in agriculture is moving in the same direction. In the future, a farm could be populated by a large number of small, autonomous robots operating in different fields at the same time, performing the equivalent work of one large machine.

As robots become scale neutral and cost effective, they could equally benefit large-scale and small-scale farmers. Smallholders in rural areas could use apps such as Uber-fortractor to book and hire expensive agricultural equipment, which would have been beyond their reach previously (Vota 2017). They might also find ways to share the fixed costs of small robots with other smallholder farmers through associative institutional designs.

Since most of the rural land is farmed by smallholders, it is essential to figure out how to adopt and incorporate technology to ensure that they can benefit from it. The key is to lower costs to make it sustainable. Access to numerous cheap and smaller robots that can work 24/7 could solve big agricultural production problems. For example, "AgBots" could reduce the cost of weed operations by $90 \%$ by cutting pesticide use (Corke 2015).

Farming is becoming a complex information space. From risk management of farm operations to special analytics, farming technology is advancing rapidly. Examples:

- Evidence-based agriculture decision support. There are key factors that might affect crop yields, including soil temperature, moisture levels, crop stress, pests, and diseases. IBM's Watson Decision Platform for Agriculture comprises artificial intelligence and cloud solutions that generate evidence-based insights into these key factors (Wiggers 2018). Watson can identify pests based on drone imagery. Its smartphone app can identify crop disease. It can also identify the best practices for irrigation, planting, and fertilization, and indicate the ideal time of the year to sell a given crop.

- Potato: yield, pest, and diseases. Satellite remote sensing and GIS techniques have been employed to forecast potato yields and detect blight disease and whiteflies. A smartphone app developed by Penn State University's PlantVillage and the International Institute of Tropical Agriculture gives farmers real-time diagnoses of crop diseases using AI algorithms trained with images of diseased crops (Kreuze 2019). The PlantVillage app detects diseases in sweet potato and monitors the spread of caterpillar in around 70 countries.

- Automatic fruit grading and counting. Cognitive image processing and computer vision techniques can support harvest by providing automated fruit grading, ripeness detection, fruit counting, and yield prediction-timeconsuming tasks that are prone to human error (Mavridou 


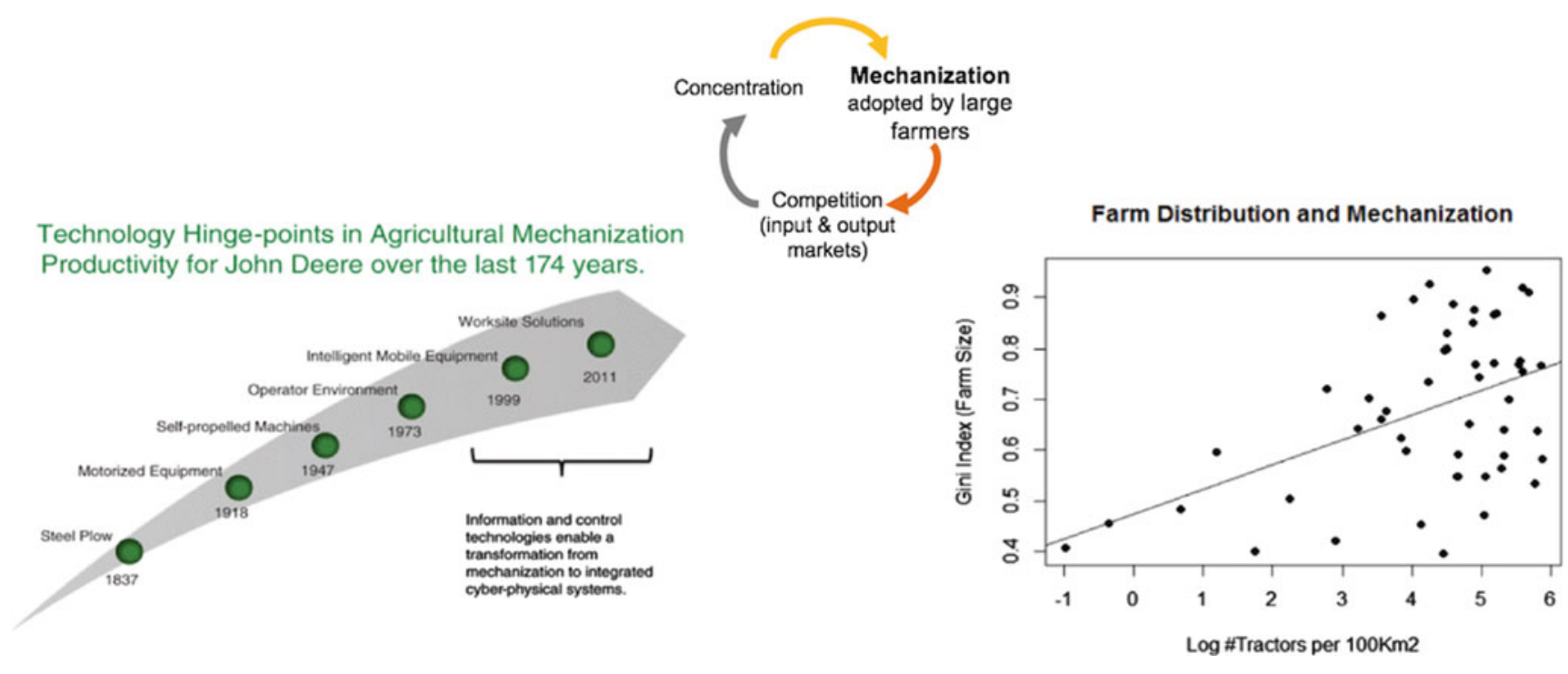

Fig. 1 Past mechanization resulted in concentrated agriculture sector. Source: Reid (2011), reprinted with permission from the National Academy of Engineering

et al. 2019). Machine vision can also protect plant health by detecting deficiencies and diseases using clustering based on color features.

- Crop-harvesting robots. The automatic harvester from Harvest CROO Robotics mimics human pickers, without changing how farmers grow their crop (Harvest CROO 2020). The use of multiple robotic components to separate the picking functions-leaf gathering, visual inspection, picking, and then packing - makes it possible to build a simple robot, which can operate faster. It takes a robot harvester $8 \mathrm{~s}$ to pick a single strawberry plant; $1.5 \mathrm{~s}$ to move to the next plant. A single robot harvester can work eight acres a day, which is equivalent to the work of 30 human laborers.

- Soil and water management. Traditionally farmers have used chemical analysis to test the quality of their soil, a complex and time-consuming method. It has created a barrier for smallholder farmers. In many rural areas of Africa, Asia, and Latin America, farmers are accruing debts to purchase packages of soil, but it does not help them achieve higher yields, because they do not know the condition of the soil they are purchasing. IBM's AgroPad, a smartphone app, is a paper-based analysis of soil that could provide the kind of information smallholder farmers need (Steiner 2018). Using sensors and AI algorithms, the app lets farmers understand the chemical make-up of their soil and also monitor the health of soil and water. It is low cost, and the paper-based device can be mass produced and deployed at a large scale through mobile and cloud technologies.

- Crop price prediction. FAO's Agricultural Market Information System (FAO-AMIS) uses machine learning to perform sentiment-based market prediction and crop forecasting to predict prices of wheat, maize, rice, and soybeans (Agricultural Market Information System 2020). Based on supply-and-demand position data, as well as satellite information calibration and testing on the ground, and their probable short-term development and outliers, the system predicts prices. It does so by combining the intensity of positive and negative forces, which means that when the density of positive forces is higher, it helps to predict positive price increases. To assess the market forces variables, several subject scopes are considered: monetary policy, market conditions, finance and investment, elections, negotiations, polices, regulations, energy, environment, and agriculture infrastructure are also included. The platform bolsters the preparedness and resilience to external shocks like food price surges (Fig. 2).

\section{Mechanisms to Promote Development}

The integration of robotics and $\mathrm{AI}$ in agriculture has the potential risk of alienating certain population, as digital technologies tend to be skill-biased, productivity-biased, and voice-biased. There will be challenges of achieving inclusion, efficiency, and innovation. Countries must expand access to technologies, lower costs, and scale up innovations to ensure smallholder farmers and rural households, too, become beneficiaries (Fig. 3).

\section{Create Complements to Minimize the Risks}

Rapid technological progress will make it possible for poor people to afford many digital services. But for them to do 


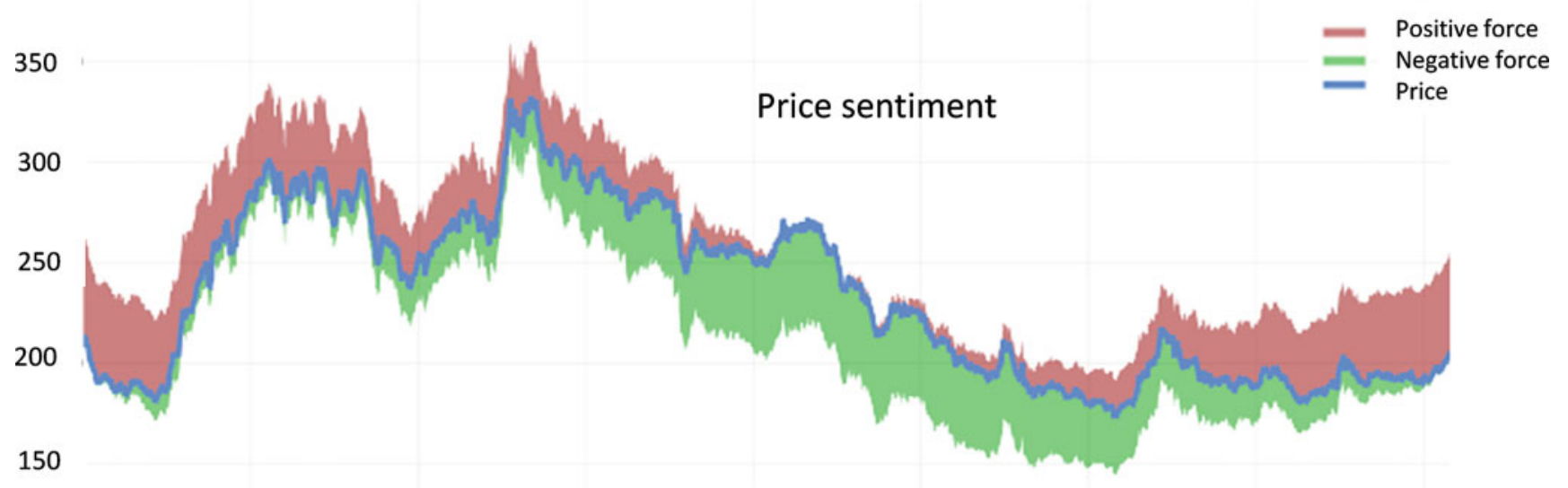

100

50

2010

2011

2012

2013

2014

2015

2016

2017

2018

Fig. 2 Agriculture Market Information System performs sentiment-based market prediction. Source: FAO-AMIS
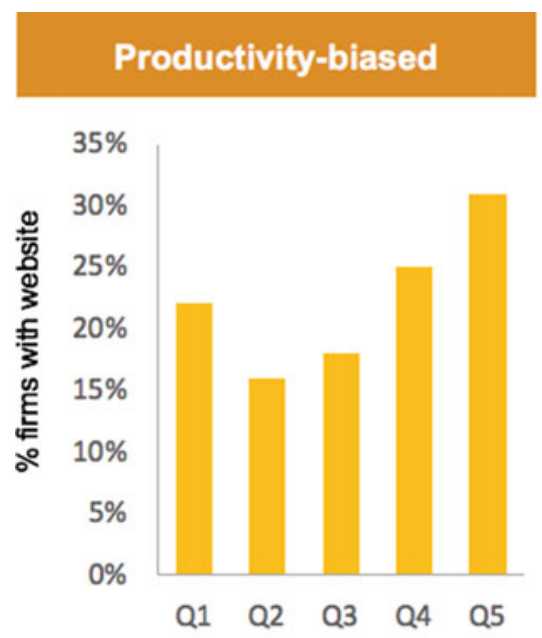

Productivity quartiles

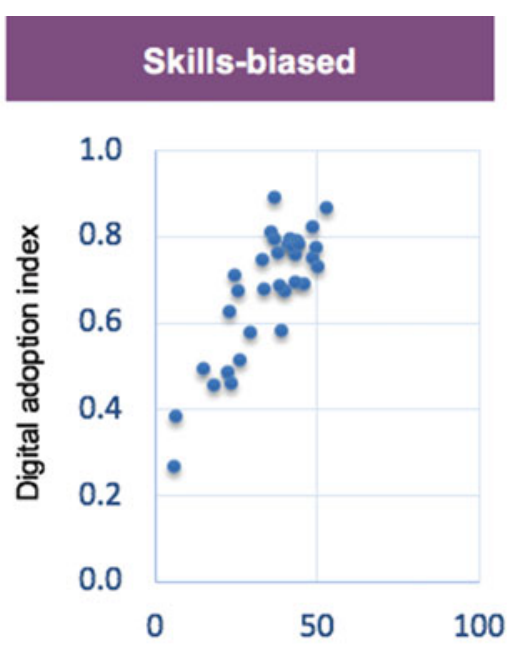

$\%$ of High ICT Intensity Occupations

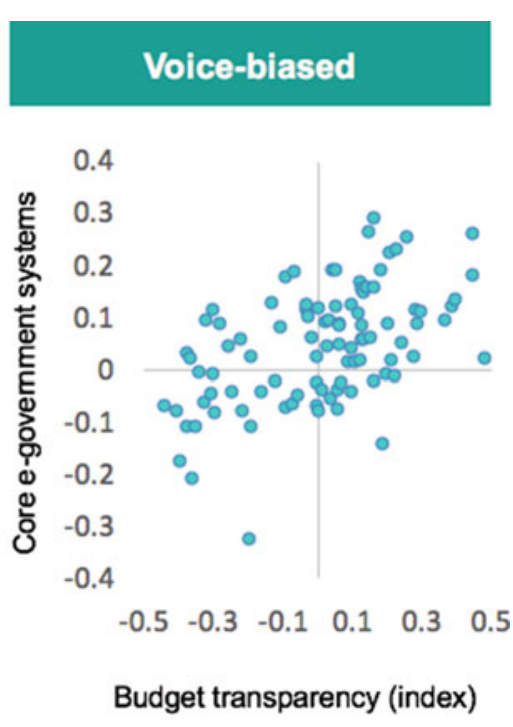

Fig. 3 Digital technologies tend to be biased. Source: World Bank Group (2016) and World Development Report Team (2016)

so, governments must invest in creating an environment that can avoid concentration of benefits and minimize inequality. Unfortunately, complements_-such as regulations promoting entry and competition, skills enabling workers to access and leverage the new economy, and institutions delivering efficient mobile phone-based services and an e-governmenthave not kept pace (Fig. 4).

The importance of providing the complements, or laying down the "analog foundations," for a new digital economy as early as possible cannot be overstated. Specifically, governments must provide an environment that ensures accessibility, adaptability, and appropriateness. This means the cost of accessing technologies should be affordable for all users. Technologies become adaptable when the content (knowledge or information) they are used to access is beneficial for users. Finally, technologies should be appropriate, which means that users must have the capability to use them (Fig. 5).

Countries should formulate digital development strategies that are broader than the current information and communication technology strategies. For example, when Ethiopia was given a loan of $\$ 500$ million from the World Bank Group to 
Fig. 4 Benefits and risks of digital technologies. Source: World Bank Group (2016) and World Development Report Team (2016)
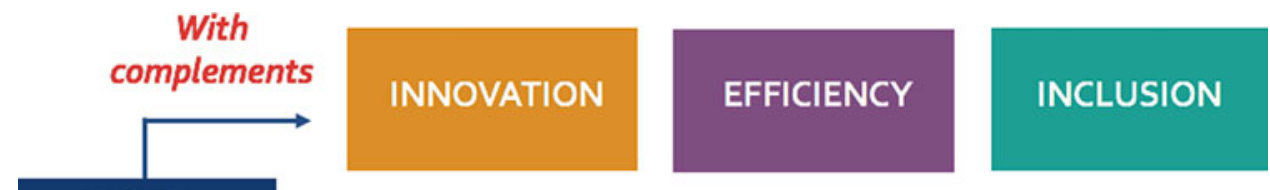

DIGITAL

TECHNOLOGIES
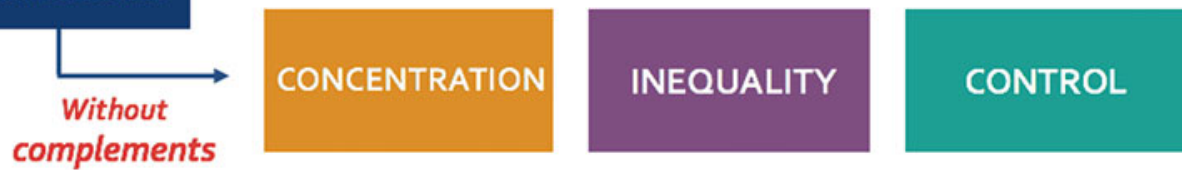
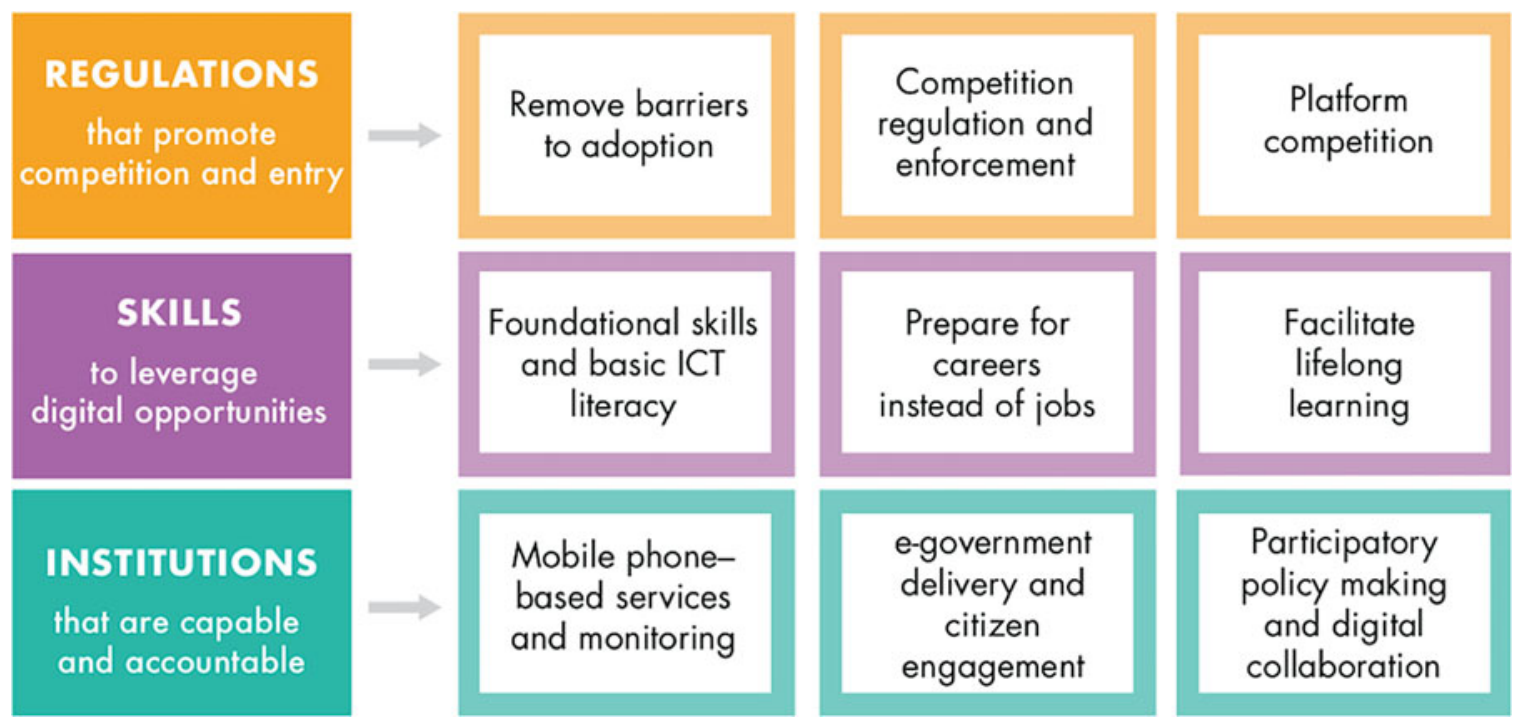

Fig. 5 National priorities: analog foundations for a digital economy. Source: World Bank Group (2016)

privatize all of its telecommunications sector, its investment plan had no regulatory mechanisms to create complements that could reduce inequality. Countries should create a policy and institutional environment for technology that fosters the greatest benefits for everyone. The quality of complements and technology both rise with incomes (Fig. 6).

Illiteracy is a potential constraint that could limit the benefits of digital technologies, as any technology will require the user to have a certain level of literacy. One way of overcoming this constraint is to work with children, as they can read and write, are more likely to be familiar with information and communication technology, and can be the bridge transferring knowledge, information and capability to their parents.

\section{Why It Matters: Robotics in Agriculture}

\section{Robots Will Address Labor Shortage}

One of the defining features of agriculture is a decrease in the available agriculture workforce, especially in Africa, Asia, and Latin America. Robotics and AI will have a significant effect on the labor markets, as they address farm labor shortage.

As stated earlier, the traditional mode of mechanization used to mean combining one worker with a large machinery to maximize the areas covered. This is no longer the case. Capabilities of these machines include being able to operate $24 / 7$, which means they will increase productivity. Subsequently, labor-intensive agriculture in low-income countries will not be economically sustainable (Fig. 7).

- New skills development. As robots address labor scarcity on the farm, it will inevitably stoke fear. But the old jobs have already been lost. Now governments must focus on increasing the skill levels that farm workers have, so that they can be integrated into the agricultural value chains. Without preparation, many people would not benefit from the advancement of digital technologies and be left behind.

- Positive social outcomes. Labor-saving technologies could free up time for women smallholder farmers. With more time, they could undertake more productive work, earn more income, and also participate in decisionmaking, which would help improve their livelihoods and 


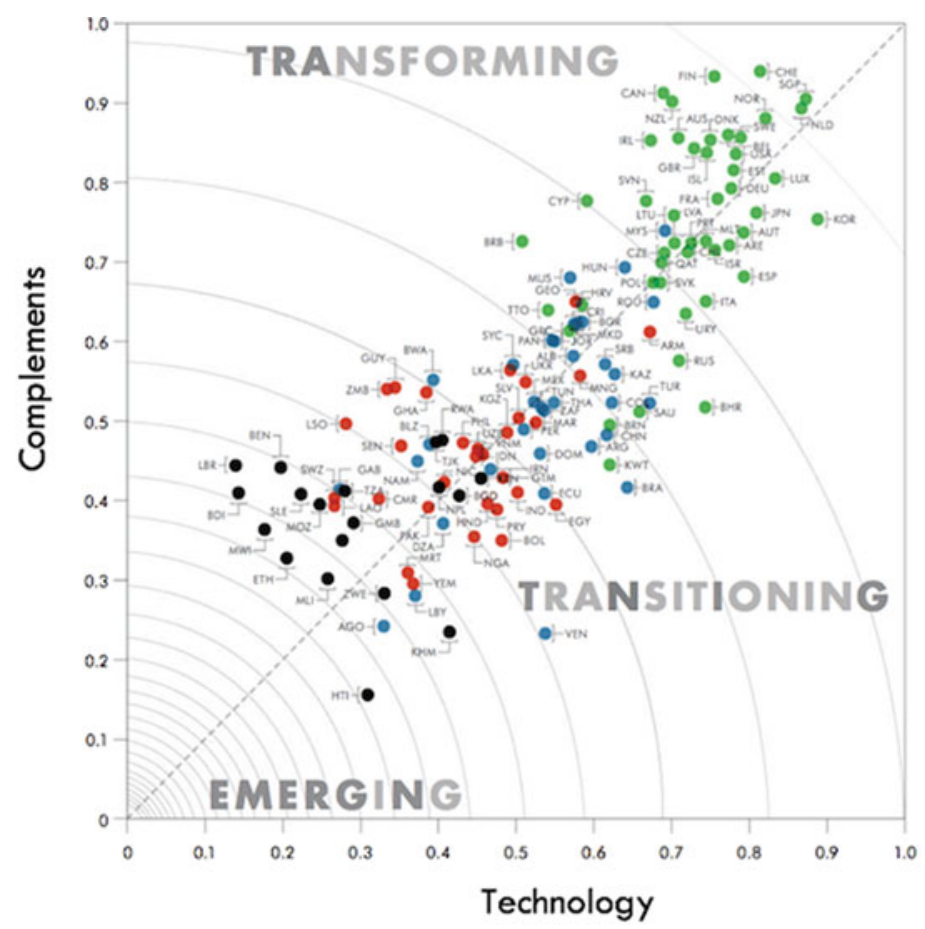

Complements: Index of quality of
institutions, skills and regulations

Technology: Digital adoption index businesses, people and governments

High-income

Upper-middle-income

Lower-middle-income

Low-income

Fig. 6 The race between technology and complements. Source: World Bank Group (2016)

Fig. 7 The forces of automation and innovation will shape future employment. Source: Glaesar (2018), cited in World Bank Group (2016)

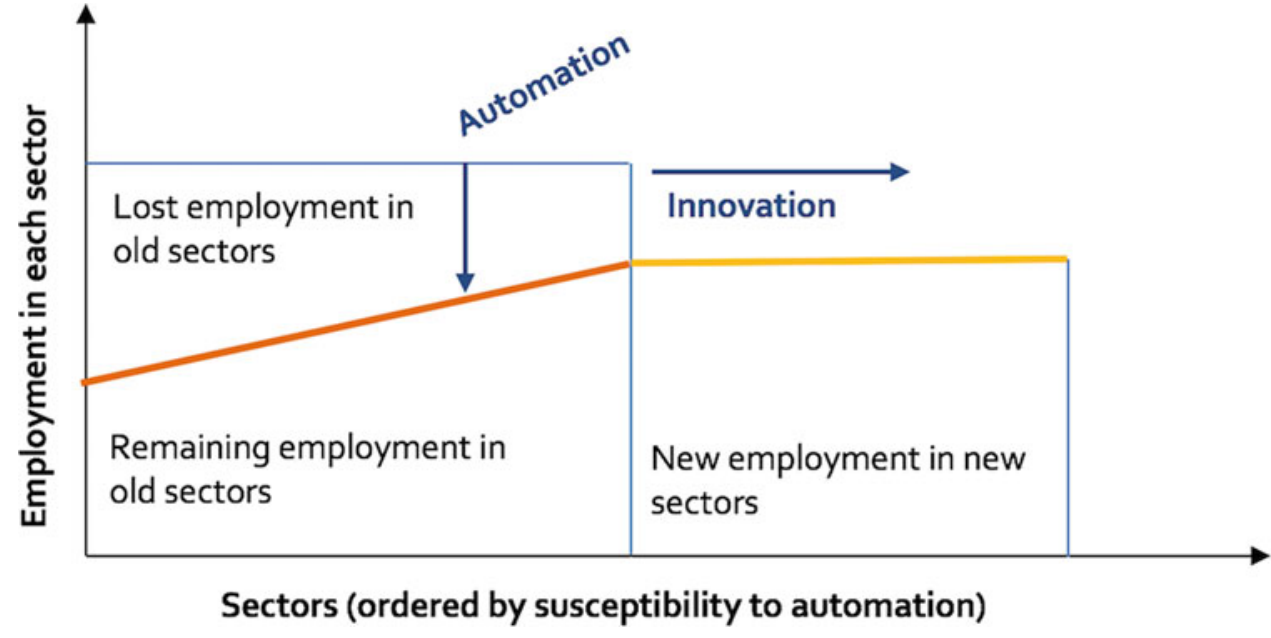

social status. Labor-saving technologies could also free up children from having to perform repetitive tasks and go back to school to receive high-quality education. ${ }^{1}$ Such technologies provide an opportunity to increase human capital.

- Youth employment. Digital agriculture represents an opportunity for young people. Farming used to mean arduous physical labor, exposure to harsh weather conditions, and repetitive tasks. Suddenly, it has become a sector with robots that appeals to young people. There would be new service jobs in rural areas for medium- or high-

\footnotetext{
${ }^{1}$ About $59 \%$ of all children in hazardous work aged 5-17 work in agriculture (ILO 2020).
}

skilled young people who are IT specialists, engineers, or mechanics. For example, the digital advances would require a new class of skilled workforce that can handle the machines as managers and technicians. It would help reduce rural exodus.

\section{Capital and Technologies Are Opportunities for Smallholders}

New technologies that are affordable represent opportunities for smallholder households. 
- Technical opportunities. Small-size mechanization means new possibilities for remote areas, steep slopes, or soft soil areas. Previously marginal areas could be productive again. Precision farming could be introduced to farmers that have little capital. It will allow farmers to adopt climate-smart practices. Farmers can be providers and consumers of data, as they link to cloud technologies using their smartphones, connecting to risk management instruments and track crop damage in real time.

- Economic opportunities. Buying new machinery no longer means getting oneself into debt thanks to lowrisk premium, better access to credit and leasing options, and more liquid renting markets. There is a reduced risk of concentration due to capital constraint. The reduced efficient scale of production means higher profitability for smallholders.

Robots in the field also represent opportunities for income diversification for farmers and their family members. There will be no need to use family labor for low productivity tasks, and time can be allocated for more profit-generating activities. Additionally, robots can operate 24/7, allowing more precision on timing of harvest, especially for high-value commodities like grapes or strawberries.

\section{Quantifying Robots' Impact on Poverty}

There are sunk cost and entry cost into any market (Sutton 1991). Evidence shows that sunk costs may contribute to either an increase or a decrease in industry concentration, depending on how the cost components are distributed. If entering into a market with certain technologies requires significant investment, it could be a factor that discourages market entry, resulting in exclusion. Governments have to find innovative ways to make market entry easier.

In an ongoing study, researchers ran a simulation exercise to quantify the impact of technology on poverty. ${ }^{2}$ Using a generic weed-picking robot, they applied the effects of laborsaving technologies to crop producers. Such a robot costs $\$ 10,000$ or an average of annual cost of $\$ 3000$ for a five-year life expectancy or an hourly rental of $\$ 0.07$. Potentially, the weed-picking robot could work $61,320 \mathrm{~h}$ annually. Labor requirement for manual weeding would have taken 377 people per hectare per hour.

Using 2013 as a baseline, the researchers ran a dynamic multi-country, multi-sector general equilibrium model, MIRAGRODEP (Agrodep 2013). ${ }^{3}$ The researchers simulated a labor-saving technological shock (not a total factor pro-

\footnotetext{
${ }^{2}$ Laborde and Torero (in progress). "The Effects of Digitalization." ${ }^{3}$ MIRAGRODEP is a new version of the MIRAGE model of the world economy.
}

ductivity shock) on all crop producers looking at increases in services costs (renting of the robot), decreasing required amount of hired labor, reducing the amount of household labor, and how this affects cost structure, labor demand, and services demand. Finally, they assessed the effects on wages, input and output prices, and poverty impacts using the $\$ 1.90$ Purchasing Power Parity poverty line.

A preliminary simulation assuming a $20 \%$ labor productivity-saving technology was run for two scenarios. Scenario 1 was "exclusive" technologies, which meant the productivity shock affected the whole agricultural sector, but not the smallholders. Therefore, poor people would benefit from higher wages (potentially) and lower food prices. Scenario 2 was "inclusive" technologies, and the productivity shock could include the smallholders. In this case, smallholders would benefit from the productivity gains for their own production.

As shown in Fig. 8, there were important reductions in the number of poor people in both scenarios, because of the labor productivity shock, resulting from the use of automatization. But the reductions were significantly higher for inclusive technologies. Notwithstanding important assumptions behind these simulations, the results clearly indicate that there is a lot of potential for these new labor-saving technologies, and that it is extremely important they reach smallholders. Unlike in the past, it is possible to be inclusive since there is a significant opportunity for "adoption at scale."

\section{Challenges}

It is worth reiterating a number of challenges that need to be overcome to ensure digital technologies are innovative, efficient, and inclusive.

- Innovation for smallholders. It is essential to provide useful and relevant information and knowledge to users. Providing access to the technology is of course important, but it would be rendered useless, if the content cannot be adapted by smallholders.

- Energy supply. Countries must focus on sourcing energy supply for robotics at scale. Renewable energy, especially solar energy with its consistently declining prices, have a vital role to play.

- Value chain. As jobs are created and eliminated with the advancement of digital technologies, agriculture value chains must be developed to harness their benefits and create higher-wage jobs, as previous laborers become managers of machinery. It provides an ideal opportunity to minimize inequalities and develop human capital.

- Connectivity. Robotics innovation requires the right intellectual property system. Governments must also put regulations in place to reduce the risk of oligopoly. New 


\section{Changes in number of poor people (Mios)}

anclusive to smallholders Exclusive to smallholders

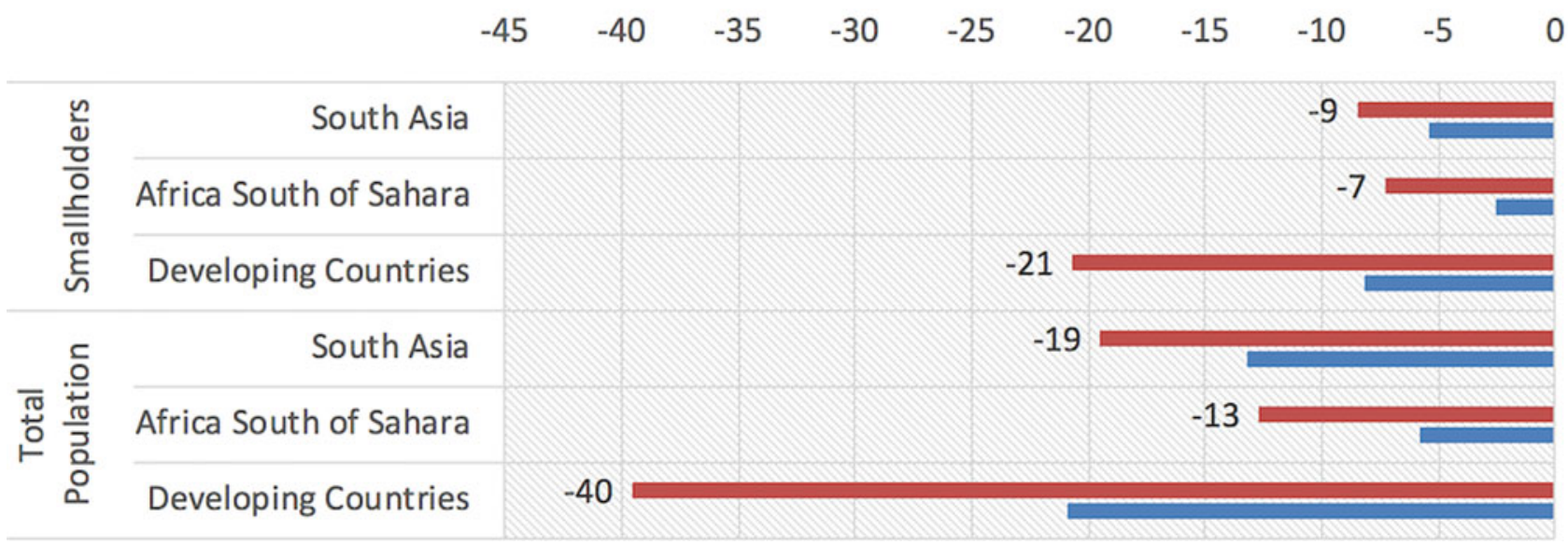

Fig. 8 Labor-saving technologies can help reduce the number of poor people. Source: Laborde and Torero (work in progress)

connectivity should protect data collected on the farm. Cyber-security concerns for farm robots should be addressed.

- Complements. Governments must invest in developing human capital, policy and accountable institutions to lay the foundation for smallholders and rural households to participate in a new digital economy.

- Capabilities. Fighting illiteracy is a key strategy in the effort to promote inclusive digital revolution. Without investing in human capital, especially quality education and integration of women in the workforce, it is not possible to minimize exclusion. Upward inter-generational transfer of knowledge is an option that has been tested successfully in different regions.

\section{References}

Agricultural Market Information System. (2020). Retrieved February 3, 2020, from http://www.amis-outlook.org/.

Agrodep. (2013). http://www.agrodep.org/model/miragrodep-model

Corke, P. (2015). Robots in agriculture. https://www.youtube.com/ watch? $\mathrm{v}=\mathrm{Q} 69 \mathrm{RVHy}-\mathrm{Xbw} \& \mathrm{t}=2 \mathrm{~s}$

FAO. (2018). The future of food and agriculture: Alternative pathways to 2050. http://www.fao.org/3/I8429EN/i8429en.pdf

FAO. (2019). Water scarcity-One of our greatest challenges of all time. Available via FAO. http://www.fao.org/fao-stories/article/en/c/ $1185405 /$

FAOSTAT. (2020). Retrieved February 3, 2020, from http:// www.fao.org/faostat/en/\#data.

Harvest CROO Robotics. (2020). https://harvestcroo.com/about/ \#technology-highlights

ILO. (2020). Child labour in agriculture. Available via ILO. https:// www.ilo.org/ipec/areas/Agriculture/lang\%2D\%2Den/index.htm

Kreuze, J. (2019). The bots are here and they're protecting our crops. Available via Scientific American. https:// blogs.scientificamerican.com/observations/the-bots-are-hereand-theyre-protecting-our-crops/

Laborde, D., \& Torero, M. (in progress). The effects of digitalization.

Lowder, S. K., Skoet, J., \& Raney, T. (2016). The number, distribution of farms, smallholder farms, and family farms worldwide. World Development, 87, 16-29. https://doi.org/10.1016/j.worlddev.2015.10.041.

Mavridou, E., Vrochidou, E., Papakostas, G. A., Pachidis, T., \& Kaburlasos, V. G. (2019). Machine vision systems in precision agriculture for crop farming. Journal of Imaging, 5(12), 89. https://doi.org/10.3390/ jimaging 5120089 .

Owen, J. (2005). Farming claims almost half Earth's land, new maps show. Available via National Geographic. https:// www.nationalgeographic.com/news/2005/12/agriculture-foodcrops-land/

Reid, J. F. (2011). The impact of mechanization on agriculture. $\mathrm{Na}$ tional Academy of Engineering, 41(3), 22-29. Available via National Academy of Engineering. https://www.nae.edu/52645/The-Impactof-Mechanization-on-Agriculture.

Schmitz, A., \& Seckler, D. (1970). Mechanized agriculture and social welfare: The case of the tomato harvester. American Journal of Agricultural Economics, 52(4), 569-577. https://doi.org/10.2307/ 1237264.

Searchinger, T., Hanson, C., Ranganathan, J., Lipinski, B., Waite, R., Winterbottom, R., Dinshaw, A., \& Heimlich, R. (2013). The great balancing act: Creating a sustainable food future, installment one. Available via World Resource Institute. https://www.wri.org/ publication/great-balancing-act

Steiner, M. (2018). AI-powered technology will help farmers' healthcheck soil and water. Available via IBM https://www.ibm.com/blogs/ research/2018/09/agropad/

Sutton, J. (1991). Sunk costs and market structure. Cambridge: MIT Press.

Torero, M. (2016). Scenarios on climate change impacts for developing APEC economies. https://maximotorero.files.wordpress.com/2020/ 02/scenarios-on-climate-change-impacts-for-developing-apececonomies.pdf

Vermeulen, S. J., Campbell, B. M., \& Ingram, J. S. I. (2012). Climate change and food systems. The Annual Review of Environment and Resources, 37, 195-222. https://doi.org/10.1146/annurev-environ020411-130608. 
Vota, W. (2017). Uber for tractors is really a thing in developing countries. Avalabe via ICTworks. https://www.ictworks.org/uber-fortractors-is-really-a-thing-in-developing-countries/\#.XkvPx0BFyUl

Wiggers, K. (2018). IBM's Watson agriculture platform predicts crop prices, combats pests and more. Available via Venturebeat. https://venturebeat.com/2018/09/24/ibms-new-ai-platform-foragriculture-predicts-crop-prices-combats-pests-and-more/

World Bank. (2019a). Agriculture and food. Available via World Bank. https://www.worldbank.org/en/topic/agriculture/overview
World Bank. (2019b). World development report 2019: The changing nature of work. Washington, DC: World Bank. https:// openknowledge.worldbank.org/handle/10986/30435.

World Bank Group. (2016). World development report 2016: Digital dividends. Washington, DC: World Bank. https:// openknowledge.worldbank.org/handle/10986/23347.

World Development Report Team. (2016). Digital dividends presentation. Washington, DC: World Bank. Available via http:/ /pubdocs.worldbank.org/en/668301452797743927/WDR-2016Overview-Presentation-DC-launch.pdf.

Open Access This chapter is licensed under the terms of the Creative Commons Attribution 4.0 International License (http://creativecommons. org/licenses/by/4.0/), which permits use, sharing, adaptation, distribution and reproduction in any medium or format, as long as you give appropriate credit to the original author(s) and the source, provide a link to the Creative Commons license and indicate if changes were made.

The images or other third party material in this chapter are included in the chapter's Creative Commons license, unless indicated otherwise in a credit line to the material. If material is not included in the chapter's Creative Commons license and your intended use is not permitted by statutory regulation or exceeds the permitted use, you will need to obtain permission directly from the copyright holder. 